\title{
Lower Susceptibility of Laser-irradiated Ti-15Mo Surface to Methicillin-resistant Staphylococcus aureus Cells Adhesion
}

Fernando Pozzi Semeghini Guastaldi **0, Camila Cristina de Foggi ${ }^{b}$, Luis Carlos Leal Santana ${ }^{a}$,

Luis Geraldo Vaz ${ }^{b}$, Carlos Eduardo Vergani ${ }^{b}$, Antonio Carlos Guastaldi ${ }^{c}$

${ }^{a}$ Departamento de Diagnóstico e Cirurgia, Universidade Estadual Paulista (Unesp), Faculdade de Odontologia de Araraquara, Araraquara, SP, Brasil

${ }^{b}$ Departamento de Materiais Dentários e Prótese, Universidade Estadual Paulista (Unesp), Faculdade de Odontologia de Araraquara, Araraquara, SP, Brasil

${ }^{c}$ Departamento de Físico-Quimica, Universidade Estadual Paulista (Unesp), Instituto de Química de Araraquara, Araraquara, SP, Brasil

Received: January 08, 2019; Revised: May 16, 2019; Accepted: June 26, 2019

Extensive data reported the influence of the physicochemical properties on the bacterial adhesion in biomaterials, of which surface roughness of titanium (Ti) can dictates methicillin-resistant Staphylococcus aureus (MRSA) adhesion to orthopedic implants. Herein, we investigated the influence of the Yb:YAG laser texturing of titanium-15molybdenum (TiMo-L) surface on the MRSA (ATCC \#33591) cells adhesion and viability. The physicochemical properties and antibacterial performance of TiMo-L were compared to samples of laser-irradiated pure titanium (Ti-L). Polished samples (Ti-P and TiMo-P) were used as controls. Laser textured surfaces presented a high degree of hydrophilicity, an irregular-shaped cavity and a typical microstructured pattern, compared to the polished substrates. The laser irradiation reduced the peaks of molybdenum (Mo) in the surface of Ti-15Mo alloy, which is explained, at least in part, by the difference between the melting point of $\mathrm{Ti}\left(1.668{ }^{\circ} \mathrm{C}\right)$ and $\mathrm{Mo}$ $\left(2.623{ }^{\circ} \mathrm{C}\right)$. Laser texturing raised the MRSA cells viability and statistically increased the bacterial adhesion to pure Ti $(\mathrm{P}<0.01$; Wilcoxon-Signed rank test $)$ and Ti-15Mo alloy $(\mathrm{P}<0.001$; Paired $t$ test $)$. The TiMo-L surface was significantly less susceptible to MRSA cell adhesion compared to Ti-L substrate $(\mathrm{P}<0.001$; Paired $\mathrm{t}$ test).

Keywords: Biological adhesion, methicillin-resistant Staphylococcus aureus, surface treatment, titanium and alloys.

\section{Introduction}

Titanium (Ti) and Ti-based alloys have been used as implantable biomaterials in orthopedic surgery ${ }^{1}$ and oral rehabilitation of edentulous patients ${ }^{2}$, because of their excellent properties such as adequate mechanical strength, resistance to corrosion ${ }^{3,4}$, and biocompatibility in vivo ${ }^{5-7}$.

Yet, titanium-6aluminium-4vanadium (Ti-6Al-4V) alloy is often the material of choice used to produce biomedical implant components $^{8-11}$, prosthetic stems for total hip arthroplasties ${ }^{12}$, and prosthetic devices for mandible reconstructions ${ }^{13,14}$, due to its superior mechanical strength compared to commercially pure titanium (cpTi) ${ }^{15}$.

However, in a physiological in vivo environment, oxide dissolution or micro-scale corrosion of Ti-6Al-4V alloy may result in metal ion release to the surrounding tissues ${ }^{16}$, and the possible occurrence of aluminum toxicity; which is associated with neurodegenerative disorders including Alzheimer and Parkinson diseases ${ }^{17}$. Moreover, toxicity related to vanadium was reported in vitro and in vivo ${ }^{18}$.
The development of multifunctional biocompatible materials with excellent mechanical properties, electrochemical stability and resistance to microorganisms adhesion, has been extensively researched in biomedical sciences. To overcome the possible adverse effects of Ti-6Al-4V, current research addressed the synthesis of new biomaterials composed of nontoxic elements, such as tantalum $(\mathrm{Ta})$, niobium $(\mathrm{Nb})$, zirconium $(\mathrm{Zr})$ and molybdenum (Mo) $)^{5,7}$. Thus, Ti-Mo alloys received great attention due to its electrochemical stability, low elasticity modulus and higher corrosion resistance in physiological-simulated media result, indeed the ions exist in the surrounding implant tissue, particularly $\mathrm{Ti}-15 \mathrm{Mo}^{3,7}$.

Another important aspect to consider is the morphology and physicochemical properties of implants surface to improve bone-implant osseointegration ${ }^{19,20}$. Different techniques have been proposed to modify implant surface characteristics, such as ion deposition, surface coatings, sand blast and acid-etch treatments, plasma spray, laser-beam irradiation ${ }^{21}$ and microarc oxidation ${ }^{22}$. Plasma electrolytic oxidation, also known as micro-arc oxidation, is similar to conventional anodizing, 
except that higher voltages are used to disrupt the oxide layer of Ti substrates until the grow of a thick protective oxide coating ${ }^{23}$. On the other hand, electropolishing is an electrochemical method used to produce smooth surfaces by controlled dissolution of Ti substrate in acid solution ${ }^{24}$.

Regarding implants surface modifications, it has been documented the favorable effects of laser beam irradiation on Ti implants osseointegration; which occurred in a shorter period compared to non-irradiated groups ${ }^{25-27}$. In fact, a positive correlation was observed between specific physicochemical properties and higher surface roughness, that increased removal torque values among laser irradiated implants ${ }^{26}$. Recently, it was demonstrated that laser irradiation greatly enhanced biomechanical properties and the osseointegration of biomedical Ti-15Mo implants in vivo ${ }^{7}$.

However, although increased surface roughness may improve bone-implant contact ${ }^{28}$, it is reasonable to assume that it may also favor the bacterial adhesion to Ti surfaces ${ }^{29}$. In fact, Staphylococcus aureus (S. aureus) has preferential adhesion to Ti-6Al-4V alloy compared to other orthopedic biomaterials ${ }^{30}$, which is partially explained by different properties such as the chemical composition of the material, surface morphometry, surface energy, degree of hydration, electrostatic charge, hydrophobicity/hydrophilicity, and Van der Waals forces among others ${ }^{31,32}$.

S. aureus, including methicillin-resistant $S$. aureus (MRSA), is a major concern in orthopedic surgery because is often associated to surgical site infections ${ }^{33}$, which is one of the main causes for surgical revision in total hip arthroplasties ${ }^{34}$. Nevertheless, there is a paucity of data regarding the influence of physicochemical properties of laser-irradiated Ti-15Mo on MRSA cells adhesion. Therefore, the purpose of this in vitro study was to evaluate the surface topography and the physicochemical properties of Ti-15Mo alloy after laser-beam irradiation and the influence of laser irradiation on MRSA cell adhesion to Ti-15Mo surface.

\section{Materials and Methods}

\subsection{Samples preparation and experimental groups}

Ti-15Mo (in wt \%) samples (developed by the Biomaterials Group, Institute of Chemistry of Araraquara, UNESP) were casted in an arc-melting furnace with inert argon atmosphere, as described elsewhere ${ }^{7}$. Twelve disks (with 10-mm diameter and 2-mm thickness) made of Ti-15Mo alloy and grade 2 cpTi (Titanews, Barueri, SP, Brazil) were used. First, the samples were ground under demineralized water with $\mathrm{SiC}$ sandpapers until grit size 600 . Thereafter, the disks were ultrasonically cleaned in distilled water, acetone and ethanol for $10 \mathrm{~min}$ each, and then, air dried at room temperature.

Half of the disks had their surface treated with laserbeam irradiation using a pulsed laser Yb:YAG (Pulsed Ytterbium Fiber Laser, Ominitek Tecnologia Ltda, Brazil).
The following laser-beam parameters were used: fluency (density power inside irradiated surface) $1,9 \mathrm{~J} / \mathrm{cm}^{2}$, scanning speed $0-200 \mathrm{~mm} / \mathrm{s}$, pulse frequency $20-35 \mathrm{kHz}$ and average exposure area $14 \mathrm{~mm}^{2}$. After the surface irradiation, the samples were ultrasonically cleaned as mentioned before. A total of four groups were evaluated: 1) polished cpTi (Ti-P); 2) laser irradiated cpTi (Ti-L); 3) polished Ti-15Mo alloy (TiMo-P) and 4) laser irradiated Ti-15Mo alloy (TiMo-L). Polished samples served as respective control group for either laser irradiated cpTi or Ti-15Mo specimens.

\subsection{Surface topography and physicochemical characterization}

The surface topography of the studied samples, before and after laser irradiation of the surfaces, was analyzed by using field-emission gun scanning electron microscopy (FEG-SEM; Jeol 7500F; Jeol, Peabody, MA, USA), whereas energy dispersive X-ray (EDX) spectroscopy was used to check the chemical composition or detect any contamination of the materials.

\subsection{Wettability analysis}

The wettability of the samples was evaluated by contact angle measurement using a contact angle tester OCA-15 (Dataphysics, Germany). Drops of distilled water were delivered onto the specimen surface by a syringe giving the same drop size. The contact angle was measured after 20 seconds and repeated 3 times for each sample.

\subsection{Surface roughness measurements}

Surface roughness measurements of all specimens were performed using a profilometer (Mitutoyo SJ 400; Mitutoyo, Tokyo, Japan), with a resolution of $0.01 \mu \mathrm{m}$, an interval (cut-off length) of $0.8 \mathrm{~mm}$, a transverse length of $2.4 \mathrm{~mm}$, a stylus speed of $0.5 \mathrm{~mm} / \mathrm{s}^{35}$. For each specimen, readings were performed at four points, and the average reading of surface roughness was designated as the $\mathrm{R}_{\mathrm{a}}$ value $(\mu \mathrm{m})$ of that specimen. All measurements were recorded by a trained operator.

\subsection{Microorganism and culture conditions}

Methicillin-resistant Staphylococcus aureus (MRSA; American Type Culture Collection 33591) was the bacterial strain used in the present study. To prepare the inoculum, a loopful of the stock culture was streaked onto Mueller Hinton agar (Himedia, Mumbai, India) and incubated at $37^{\circ} \mathrm{C}$ for $48 \mathrm{~h}$. One loopful of this young culture were transferred to $20 \mathrm{~mL}$ trypticase soy broth (TSB) culture medium (Sigma, St Louis, MO, USA) and incubated at $37^{\circ} \mathrm{C}$ for $21 \mathrm{~h}$. Bacterial cells of the resultant culture were harvested, washed twice with sterile phosphate-buffered saline (PBS) $(\mathrm{pH} 6.8)$ at $4000 \times \mathrm{g}$ for 5 min, and resuspended in TSB. Staphylococcus suspensions were spectrophotometrically standardized at an OD600nm of 0.1 , which corresponds to a final concentration of $10^{7}$ cells $/ \mathrm{mL}$. 


\subsection{Adherence assay}

Specimens of each experimental group were used for the adherence assay ( $90 \mathrm{~min}$ of incubation). Prior to the microbiological tests, the specimens were ultrasonicated in distilled water for $20 \mathrm{~min}$ and then exposed to UV light under dry conditions for another $20 \mathrm{~min}$ (each side) for sterilization. Two milliliters of the inoculum $\left(10^{7} \mathrm{cells} / \mathrm{mL}\right)$ were added to each well of a 24-well microplate containing the specimens, and then incubated at $37^{\circ} \mathrm{C}$ in an orbital shaker for $90 \mathrm{~min}$. The non-adherent cells were removed from the specimens by gently washing twice with $2 \mathrm{~mL}$ PBS after 90 min (initial adherence). After washing, the cells adhered to the specimens were removed by sonication and the assays described below were performed. For all experiments, negative controls were specimens to which no cells were added. All experiments were performed in triplicate on three independent occasions. The initial adherence of MRSA cells was evaluated by counting c.f.u. $/ \mathrm{mL}$.

\subsection{CFU method}

Viable microorganisms after the initial adherence of MRSA were quantified by counting the c.f.u. After washing the non- adherent cells with PBS, each specimen was transferred to a Falcon tube containing $10 \mathrm{~mL}$ PBS, which was vortexed vigorously for $1 \mathrm{~min}$ to resuspend the adhered cells. Cell suspensions obtained were serially diluted (from $10^{-1}$ to $\left.10^{-8}\right)$ in PBS and $10 \mu \mathrm{L}$ of each dilution plated on Mueller Hinton agar in duplicate. After $48 \mathrm{~h}$ of incubation at $37^{\circ} \mathrm{C}$, the number of colonies was counted and expressed as c.f.u. $/ \mathrm{mL}$.

\subsection{MRSA cells morphology and spreading}

MRSA cell morphology and cell distribution onto polished and laser-treated samples was determined, respectively, by FEG-SEM and confocal laser scanning microscopy (CLSM; Carl Zeiss, Germany) analysis. Briefly, MRSA cells were cultured as aforementioned, washed with PBS, and then, fixed with $2.5 \%$ glutaraldehyde for $24 \mathrm{~h}$ at room temperature. Thereafter, cells were dehydrated through a graded ethanol series $(70 \%, 85 \%$, and $100 \%)$ and sputter-coated with gold for FEG-SEM analysis. For cell distribution, MRSA cells were stained with a Live/Dead BacLight Viability Kit (Invitrogen) and marked cells were visualized using Zeiss LSM 800 CLSM.

\subsection{Statistical analysis}

Data from microbiological adhesion was subjected to Shapiro-Wilk normality test to assess whether the data followed a normal distribution. The Bartlett's test was used to determine if the assumption of homogeneity of variance was valid. If data satisfied both criteria (normality and homoscedasticity), parametric Paired t-test was performed.
The nonparametric Wilcoxon signed rank test was used when data did not adhere to normal curve. All tests were performed using Prism 5.0 (GraphPad Software, San Diego, CA, USA) and the level of significance was set to be $5 \%$.

\section{Results and Discussion}

Considerable advances have been made in understanding the bone-implant surface interaction to increase the biological response around dental implants and in the development of new implant surfaces ${ }^{26,36-38}$ (Souza et al., 2014). The morphological and physicochemical properties of dental implant surfaces are essential in the early stages of osseointegration ${ }^{37,38}$ (Al-Hamdan et al., 2012).

Since 2006, studies have been developed in our laboratories, aiming to increase the clinical predictability and acceleration of bone healing using new technologies for physicochemical and morphological modifications of implant surfaces ${ }^{7,26,27,38,39}$ (Sisti et al., 2006, 2013; Souza et al., 2013, 2014).

\subsection{Surface morphology and roughness}

Laser surface modification increase roughness and produce a larger area of bone-implant contact compared to acid etching (i.e. most common surface modification of

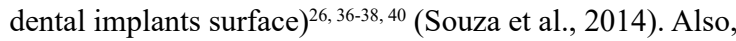
laser beam irradiation technology for surface preparation creates a unique 3D topography and maintains a rough pattern on the surface of the implant, provides an increase in hardness, and resistance to corrosion ${ }^{41-43}$.

Surface topography analysis were carried out at high resolution using FEG-SEM. Figure 1 shows the clear differences in the surface morphology between laser-irradiated (Ti-L and TiMo-L) and polished (Ti-P and TiMo-P) substrates. Thereof, a smooth surface was observed in the Ti-P and TiMo-P samples, whereas Ti-L and TiMo-L groups presented irregular-shaped cavities and a typical microstructured surface with large depressions. This results are in accordance with previous findings in which pulsed Yb:YAG laser treatment resulted in a typical macro- and micro-roughness surface on $\mathrm{cpTi}^{41,44}$ and $\mathrm{Ti}-15 \mathrm{Mo}^{7}$.

Roughness is an important property for dental implants influencing directly cellular adhesion and proliferation ${ }^{42,43,45}$. The laser irradiation increased the surface roughness measured by the $\mathrm{R}_{\mathrm{a}}$ values (average of the peak-to-valley measurements), in both cpTi and T-15Mo substrates. While Ti-P and TiMo-P presented 0.20 and $0.39 \mu \mathrm{m}$, Ti-L and TiMo-L exhibited 5.64 and $4.54 \mu \mathrm{m}$, respectively.

\subsection{Chemical composition and surface wettability}

When studying implants' surface modifications, it is extremely important to analyze the possible chemical contamination of the surface. Figure 2 shows the surface chemical composition of both cpTi and Ti-15Mo substrates. 

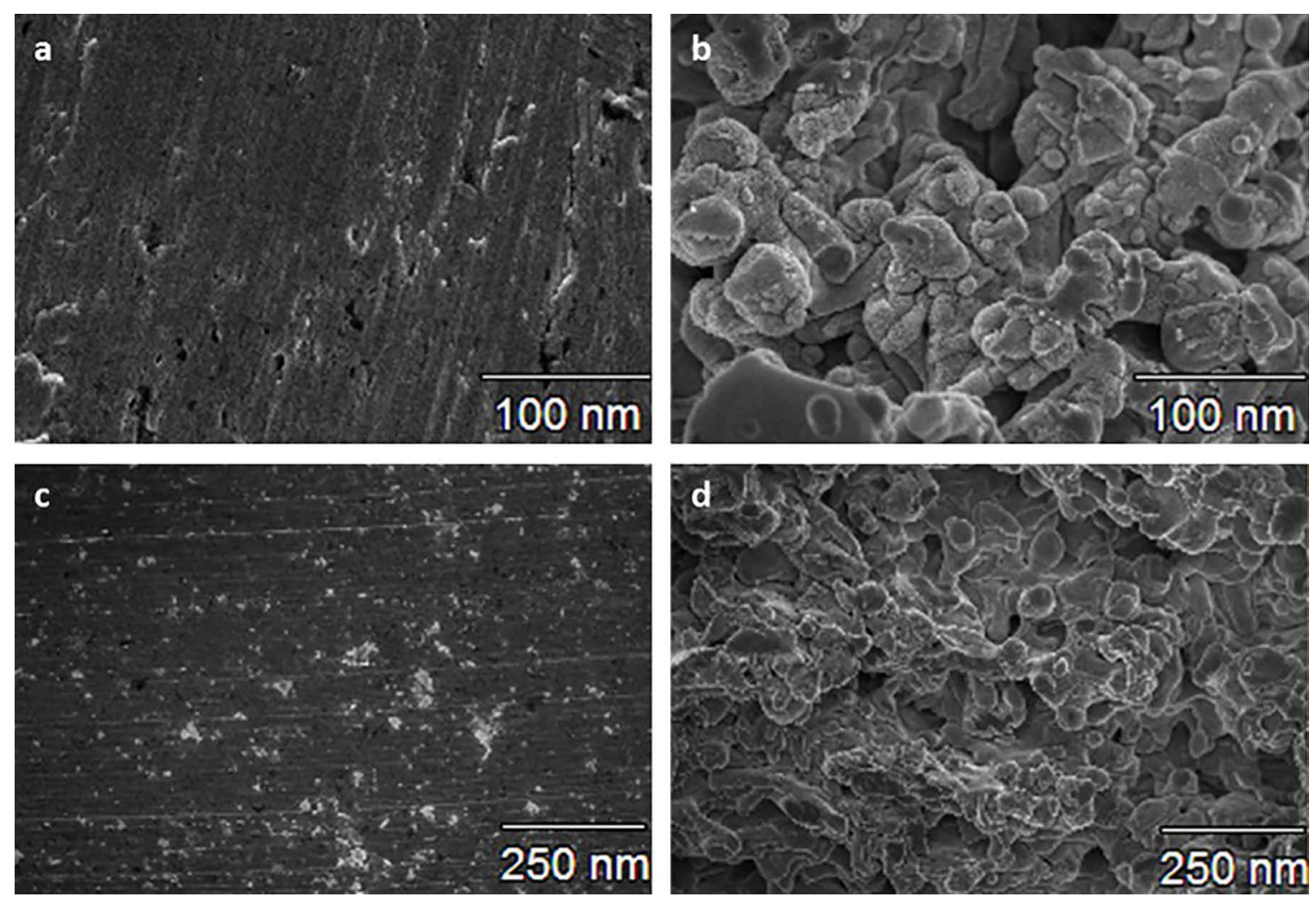

Figure 1. FEG-SEM of the: (a) Ti-P, (b) Ti-L, (c) TiMo-P and (d) TiMo-L.
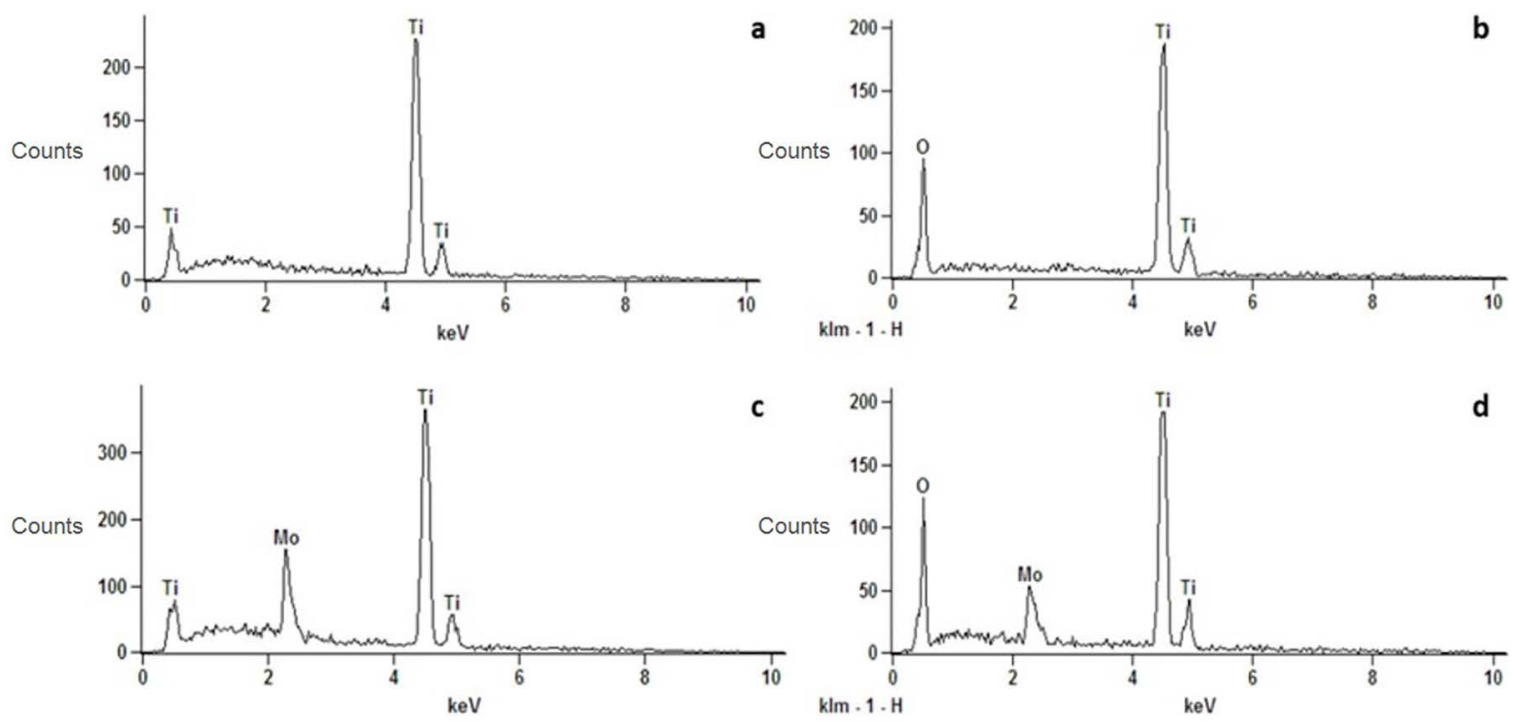

Figure 2. EDX of the: (a) Ti-P, (b) Ti-L, (c) TiMo-P and (d) TiMo-L.

The EDX spectra detected peaks of Ti, Mo and O. The laser irradiation reduced the peaks of Mo in the surface of Ti-15Mo alloy, which can be explained, at least in part, by the difference in the melting point between $\operatorname{Ti}\left(1.668^{\circ} \mathrm{C}\right)$ and $\mathrm{Mo}\left(2.623^{\circ} \mathrm{C}\right)$. Moreover, regarding the laser irradiation process, the EDX showed no trace of impurities on the surface of both Ti-L and TiMo-L samples. Similar findings were observed after the laser irradiation of the $\mathrm{cpTi}^{42,43}$ and Ti- $15 \mathrm{Mo}^{7}$ substrates.
To obtain these results the surfaces of the substrates were irradiated by laser beam under conditions that promote the phenomenon of ablation, which is directly correlated with the energy density used, leading to oxygen diffusion through the molten metal and oxidation of the alloy surface. Ablation process is characterized by a quick melting (melted metal zone formation) and solidification process in the presence of ambient atmosphere, forming stoichiometric and non-stoichiometric oxides. 
The parameters for irradiating the surface of metal implants (cpTi and Ti alloys) by laser beam were established more than 10 years ago by the Biomaterials Group (Institute of Chemistry at Araraquara/UNESP) $)^{41}$. Also, laser beam irradiation technology for surface preparation generates a high degree of purity and produces a thick layer of oxides ${ }^{41-43}$.

The contact angle values of both $\mathrm{cpTi}$ and Ti-15Mo substrates were obtained in order to evaluate the influence of laser-beam irradiation on the surface wettability. A complete wetting was observed for the laser-irradiated disks, whereas polished surfaces exhibited a higher degree of hydrophobicity. While the contact angle for Ti-P and TiMo-P was $67.9^{\circ}( \pm$ $13.01^{\circ}$ ) and $58.65^{\circ}\left( \pm 3.18^{\circ}\right)$, the contact angle from laserirradiated samples was $0^{\circ}$ for both Ti-L and TiMo-L groups, respectively (Table 1). Our results are in accordance with previous findings that reported the enhanced wettability after laser irradiation of Ti surface ${ }^{21}$. The literature reports several studies that employs the technology of laser modification of cpTi and Ti alloys, with improvements in their physicochemical properties, wear and corrosion resistance, favoring the in vivo bone response to these surfaces ${ }^{7,26,42,43}$. Hydrophilicity is considered an important factor to early bone response ${ }^{46}$. Higher surface energy and increased wettability properties are correlated to enhance the interactions between surface and the surrounding bone ${ }^{47}$, leading to faster healing and consequently early loading of dental implants ${ }^{48}$. Based on the observation of the morphology of the laser groups, rougher surfaces were obtained in the present study compared to that for Nd:YAG laser irradiation on different Ti implant material ${ }^{45}$, showing that the laser parameters employed were able to create a controllable, reproducible and clean method to modify Ti implant surface ${ }^{41}$.

Table 1. Contact angle measurements on $\mathrm{Ti}$ and Ti-Mo alloy, polished $(\mathrm{P})$ or modified by laser beam irradiation $(\mathrm{L})$.

\begin{tabular}{lc}
\hline Sample & Contact angle $\left({ }^{\circ}\right)$ \\
\hline Ti-P & $67.9 \pm 13.01$ \\
Ti-L & 0 \\
TiMo-P & $58.65 \pm 3.18$ \\
TiMo-L & 0 \\
\hline
\end{tabular}

\subsection{MRSA cells' adhesion}

The rationale for the use of antibiotic-resistant $S$. aureus is that MRSA is one of the most common pathogens associated to persistent prosthetic joint infections in primary total hip arthroplasties ${ }^{49}$. Considering it was previously documented the existence of MRSA strains isolated from infected prosthetic joints ${ }^{50}$, the development orthopedic implants (effective against microorganisms adhesion) is highly pursuit. Previous studies reported that surface topography has a significant impact on the bacterial adhesion to implant materials ${ }^{51,52}$, in which biofilm formation was found to be more evident in rougher surfaces compared to smoothie ones ${ }^{53}$.
In this context, our study is the first to acknowledge the ability of MRSA cells' adhesion onto laser-irradiated Ti-15Mo alloy. Figure $3 \mathrm{~A}$ shows that laser irradiation statistically increased MRSA cells adhesion to Ti $(\mathrm{p}<0.01)$ and TiMo $(\mathrm{p}<0.001)$ samples when compared to its respective controls (polished substrates). Bacterial adhesion to polished surfaces was statistically higher in TiMo alloy compared to Ti substrates $(\mathrm{p}<0.01)$. As shown in Figure 3B, the number of colonies on laser-irradiated samples was statistically higher in Ti compared to TiMo alloy $(p<0.001)$. Biomedical materials made of Ti$6 \mathrm{Al}-4 \mathrm{~V}$ has been extensively used in implant dentistry ${ }^{8}$ and orthopedic surgery ${ }^{12}$ to treat the lack of hard tissues, such as teeth and bone, because of their high mechanical properties, corrosion resistance, and biocompatibility ${ }^{54}$. However, the infection of cpTi and Ti alloys usually occurs after adhesion of pathogenic microorganisms and subsequent biofilm formation ${ }^{54}$.

\subsection{MRSA cells morphology and spreading}

Determining and understanding the most common pathogenic microorganisms present at the infected sites, as well as their behavior onto polished and modified Ti surfaces, can contribute to clinically manage contaminated surfaces of orthopedic implants. Figure 4A shows the MRSA cells morphology adhered to the Ti or TiMo substrates. FEG-SEM images showed a characteristic round-shape morphology of MRSA cells, with $1.14 \mu \mathrm{m}$ in diameter, adhered to cpTi and Ti-15Mo samples. As shown in Figure 4B, laser-irradiated cpTi and Ti-15Mo substrates presented more adherent cells compared to polished specimens, in which TiMo-L group exhibited fewer adherent cells compared to Ti-L group. The CLSM images presented in Figure 4C showed that both substrates (cpTi or Ti-15Mo) consisted of viable (green) MRSA cells adhered to polished or laser-treated samples. Data from CLSM analysis corroborates with FEG-SEM observations. The high wettability and the unique 3D surface topography produced by laser beam irradiation might be an explanation. It is known that MRSA cells exhibit better adhesion and growth on hydrophilic surfaces ${ }^{55}$, and a preferential growth onto Ti substrate ${ }^{30}$. Analyzing separately the results of bacterial adhesion on polished and laser-irradiated groups, they seem divergent. It can be assumed that the laser beam irradiation conducted to the decrease in the number of colonies onto TiMo surface. Also, the formation of different oxides on the surface of the TiMo alloy after laser irradiation potentially influenced these findings. The irregular-shaped cavities and the unique $3 \mathrm{D}$ surface produced by laser irradiation conducted both cpTi and Ti-15Mo substrates to present more adherent cells compared to polished specimens. Further, the increase in the specific surface area by laser irradiation directly influenced and justify these findings.

Comparing both polished groups, additional studies are required to better elucidate the reason why MRSA bacterial adhesion was more evident at TiMo than cpTi surfaces, once when considering the laser irradiated groups, a decrease in the MRSA cell adhesion was found for TiMo surfaces. 

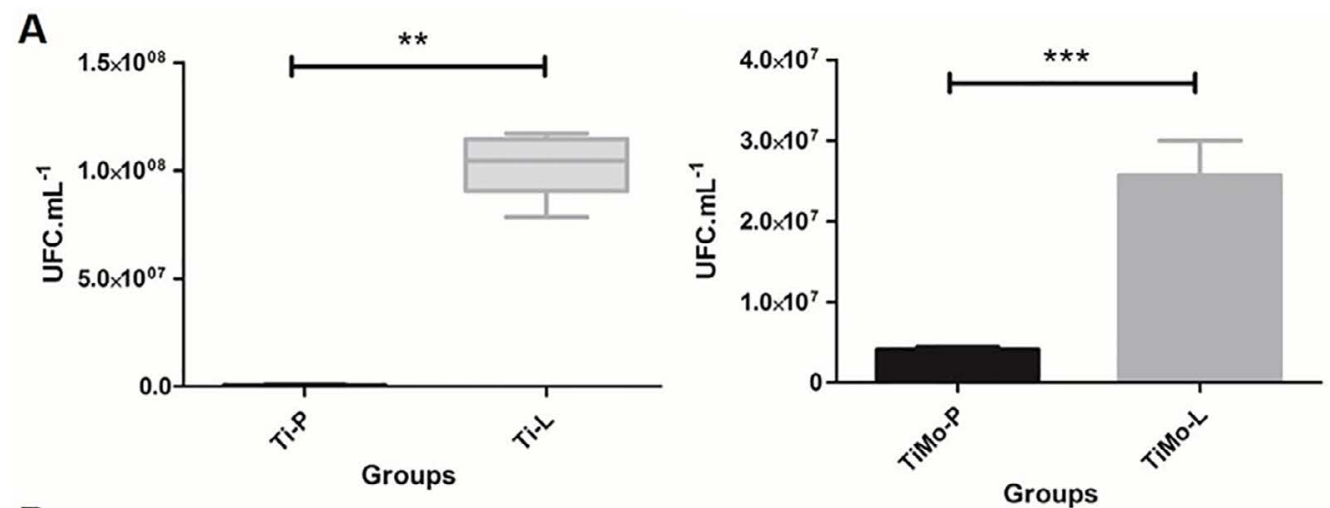

B
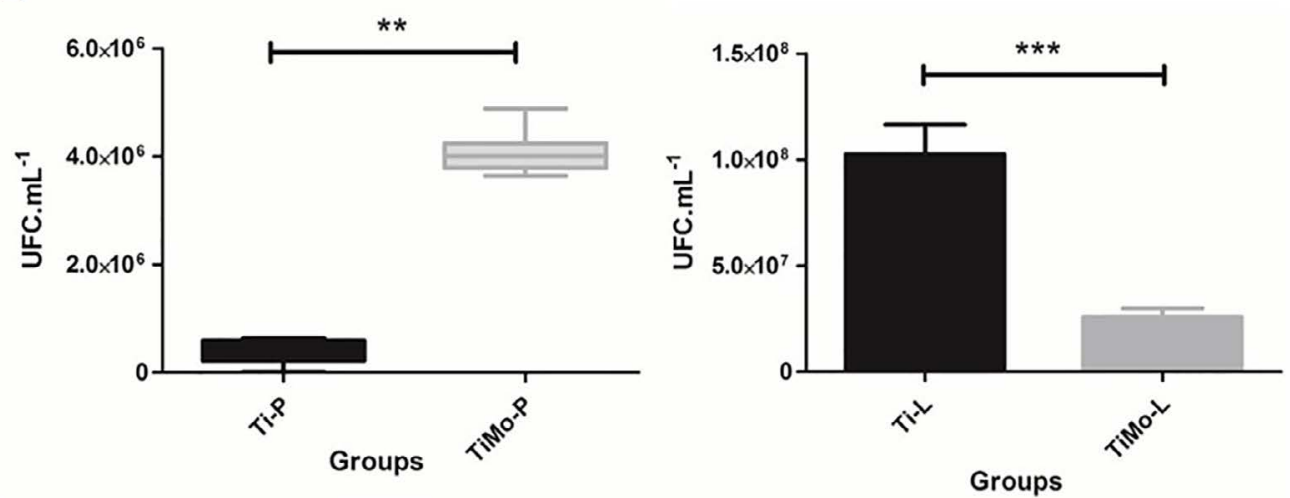

Figure 3. Graphic representation of MRSA cell adhesion to cpTi and Ti-15Mo specimens. (A) MRSA adhesion to Ti and TiMo samples was significantly higher in laser-irradiated compared to polished group ( $\mathrm{n}=9$; repeated measures). (B) MRSA adhesion to polished surface was higher in TiMo group compared to Ti; whereas in laser treated samples the bacterial adhesion was statistically higher in Ti group $(\mathrm{n}=9$; repeated measures). $* * \mathrm{P}$ value $\leq 0.01$; Wilcoxon-Signed Rank Test (Box-plot). ***P value $\leq 0.001$; Paired $\mathrm{t}$ test (Column Graphs).

Ti-P

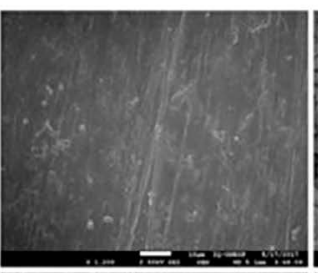

B

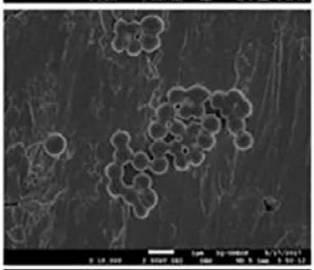

Ti-L
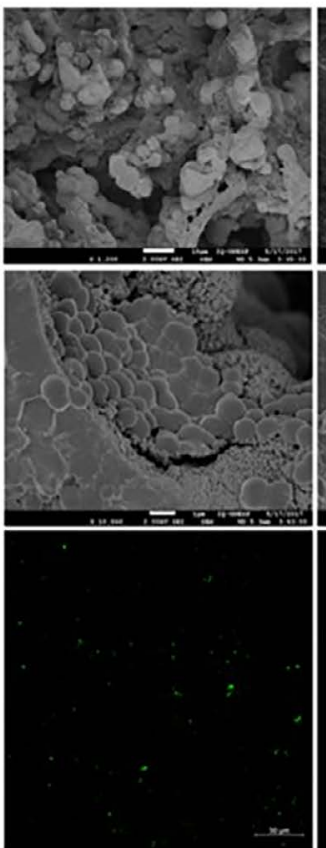

TiMo-P
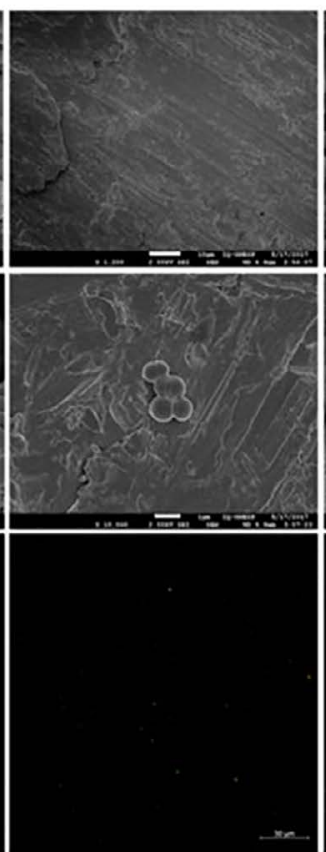

TiMo-L
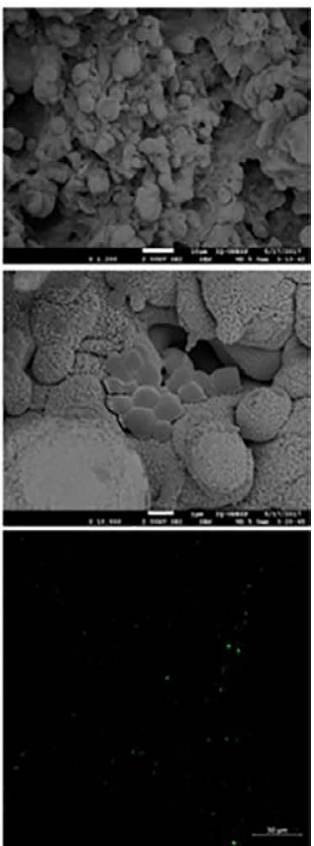

Figure 4. FEG-SEM and CLSM images of MRSA cells adhered to cpTi and Ti-15Mo specimens. (A) FEG-SEM of the surface topography of the groups with different composition. (B) Distribution and morphological characteristics of MRSA on the specimens. (C) CLSM images of living and dead cells. 
Also, the development of a coating to both polished and laser irradiated Ti-15Mo alloy surfaces to decrease the MRSA cell adhesion enabling to reduce the potential of infection represents an important strategy for the biomedical application of this alloy.

\section{Conclusions}

Based on our observations, we highlight, within the limits of an in vitro study, that pulsed $\mathrm{Yb}$ :YAG laser-beam irradiation is a feasible clean method to generate a homogeneous micro-roughness surface on cpTi or Ti-15Mo materials, apart from increase surface wettability of these materials. MRSA cells adhesion was significantly higher in laser-treated samples, in which cpTi presented a greater number of colonies per milliliters compared to Ti-15Mo alloy.

\section{Acknowledgments}

The authors would like to thank the Biomaterials Group from Institute of Chemistry of Araraquara at São Paulo State University (UNESP) for development of Ti-15Mo samples. We respectively thank to São Paulo Research Foundation (FAPESP) and the National Council for Scientific and Technological Development (CNPq) for the scholarship provided to FPSG (\#14/16688-4) and LCLS (\#168260/2017-4).

\section{References}

1. Rocco G, Fazioli F, Martucci N, Cicalese M, La Rocca A, La Manna C, et al. Video-assisted thoracic surgery rib resection and reconstruction with titanium plate. The Annals of Thoracic Surgery. 2011;92(2):744-745.

2. van Velzen FJ, Ofec R, Schulten EA, Ten Bruggenkate CM. 10 -year survival rate and the incidence of peri-implant disease of 374 titanium dental implants with a SLA surface: a prospective cohort study in 177 fully and partially edentulous patients. Clinical Oral Implants Research. 2015;26(10):1121-1128.

3. Oliveira NT, Guastaldi AC. Electrochemical stability and corrosion resistance of Ti-Mo alloys for biomedical applications. Acta Biomaterialia. 2009;5(1):399-405.

4. Biesiekierski A, Lin J, Li Y, Ping D, Yamabe-Mitarai Y, Wen C. Investigations into $\mathrm{Ti}-(\mathrm{Nb}, \mathrm{Ta})-\mathrm{Fe}$ alloys for biomedical applications. Acta Biomaterialia. 2016;32:336-347.

5. Lin DJ, Chuang CC, Chern Lin JH, Lee JW, Ju CP, Yin HS. Bone formation at the surface of low modulus Ti-7.5Mo implants in rabbit femur. Biomaterials. 2007;28(16):2582-2589.

6. Miura K, Yamada N, Hanada S, Jung TK, Itoi E. The bone tissue compatibility of a new Ti-Nb-Sn alloy with a low Young's modulus. Acta Biomaterialia. 2011;7(5):2320-2326.

7. Oliveira NTC, Guastaldi FPS, Perrotti V, Hochuli-Vieira E, Guastaldi AC, Piattelli A, et al. Biomedical Ti-Mo Alloys with Surface Machined and Modified by Laser Beam: Biomechanical, Histological, and Histometric Analysis in Rabbits. Clinical Implant Dentistry and Related Research. 2013;15:427-437.
8. Bonfante EA, Suzuki M, Lorenzoni FC, Sena LA, Hirata R, Bonfante G, et al. Probability of survival of implant-supported metal ceramic and $\mathrm{CAD} / \mathrm{CAM}$ resin nanoceramic crowns. Dental Materials. 2015;31(8):e168-177.

9. Freitas Júnior AC, Bonfante EA, Silva NR, Marotta L, Coelho PG. Effect of implant-abutment connection design on reliability of crowns: regular vs. horizontal mismatched platform. Clinical Oral Implants Research. 2012;23(9):1123-1126.

10. Medvedev AE, Molotnikov A, Lapovok R, Zeller R, Berner S, Habersetzer P, et al. Microstructure and mechanical properties of Ti-15Zr alloy used as dental implant material. Journal of the Mechanical Behavior of Biomedical Materials. 2016;62:384-398.

11. Correa DRN, Kuroda PAB, Lourenço ML, Fernandes CJC, Buzalaf NAR, Zambuzzi WF, et al. Development of Ti-15ZrMo alloys for applying as implantable biomedical devices. Journal of Alloys and Compounds. 2018;749:163-171.

12. Fokter SK, Rudolf R, Moličnik A. Titanium alloy femoral neck fracture--clinical and metallurgical analysis in 6 cases. Acta Orthopaedica. 2016;87(2):197-202.

13. Fernandes N, van den Heever J, Hoek K, Booysen G. Customized reconstruction of an extensive mandibular defect: A clinical report. The Journal of Prosthetic Dentistry. 2016;116(6):928-931.

14. Suska F, Kjeller G, Tarnow P, Hryha E, Nyborg L, Snis A, et al. Electron Beam Melting Manufacturing Technology for Individually Manufactured Jaw Prosthesis: A Case Report. Journal of Oral and Maxillofacial Surgery. 2016;74(8):1706.e1701-1706.e1715.

15. Elias CN, Fernandes DJ, Resende CR, Roestel J. Mechanical properties, surface morphology and stability of a modified commercially pure high strength titanium alloy for dental implants. Dental Materials. 2015;31(2):e1-e13.

16. El Sawy AA, Shaarawy MA. Evaluation of metal ion release from Ti6Al4V and Co-Cr-Mo casting alloys: in vivo and in vitro study. Journal of Prosthodontics. 2014;23(2):89-97.

17. Bondy SC. Prolonged exposure to low levels of aluminum leads to changes associated with brain aging and neurodegeneration. Toxicology. 2014;315:1-7.

18. Hosseini MJ, Shaki F, Ghazi-Khansari M, Pourahmad J. Toxicity of vanadium on isolated rat liver mitochondria: a new mechanistic approach. Metallomics: Integrated Biometal Science. 2013;5(2):152-166.

19. Le Guéhennec L, Soueidan A, Layrolle P, Amouriq Y. Surface treatments of titanium dental implants for rapid osseointegration. Dental Materials. 2007;23(7):844-854.

20. Le Guehennec L, Goyenvalle E, Lopez-Heredia MA, Weiss P, Amouriq Y, Layrolle P. Histomorphometric analysis of the osseointegration of four different implant surfaces in the femoral epiphyses of rabbits. Clinical Oral Implants Research. 2008;19(11):1103-1110.

21. Barfeie A, Wilson J, Rees J. Implant surface characteristics and their effect on osseointegration. British Dental Journal. 2015;218(5):E9.

22. Oliveira NTC, Aleixo G, Caram R, Guastaldi AC. Development of Ti-Mo alloys for biomedical applications: Microstructure and electrochemical characterization. Materials Science and Engineering: A. 2007;452-453:727-731. 
23. Durdu S, Deniz ÖF, Kutbay I, Usta M. Characterization and formation of hydroxyapatite on Ti6Al4V coated by plasma electrolytic oxidation. Journal of Alloys and Compounds. 2013;551:422-429.

24. Babilas D, Urbańczyk E, Sowa M, Maciej A, Korotin DM, Zhidkov IS, et al. On the electropolishing and anodic oxidation of Ti-15Mo alloy. Electrochimica Acta. 2016;205:256-265.

25. Liang C, Wang H, Yang J, Cai Y, Hu X, Yang Y, et al. Femtosecond laser-induced micropattern and $\mathrm{Ca} / \mathrm{P}$ deposition on Ti implant surface and its acceleration on early osseointegration. $A C S$ Applied Materials \& Interfaces. 2013;5(16):8179-8186.

26. Queiroz TP, Souza FA, Guastaldi AC, Margonar R, Garcia-Junior IR, Hochuli-Vieira E. Commercially pure titanium implants with surfaces modified by laser beam with and without chemical deposition of apatite. Biomechanical and topographical analysis in rabbits. Clinical Oral Implants Research. 2013;24(8):896-903.

27. Faeda RS, Tavares HS, Sartori R, Guastaldi AC, Marcantonio E Jr. Biological performance of chemical hydroxyapatite coating associated with implant surface modification by laser beam: biomechanical study in rabbit tibias. Journal of Oral and Maxillofacial Surgery. 2009;67(8):1706-1715.

28. Salvi GE, Bosshardt DD, Lang NP, Abrahamsson I, Berglundh $\mathrm{T}$, Lindhe J, et al. Temporal sequence of hard and soft tissue healing around titanium dental implants. Periodontology 2000. 2015;68(1):135-152.

29. Miranda PV, Rodrigues JA, Blay A, Shibli JA, Cassoni A. Surface alterations of zirconia and titanium substrates after Er,Cr:YSGG irradiation. Lasers in Medical Science. 2015;30(1):43-48.

30. Barth E, Myrvik QM, Wagner W, Gristina AG. In vitro and in vivo comparative colonization of Staphylococcus aureus and Staphylococcus epidermidis on orthopaedic implant materials. Biomaterials. 1989;10(5):325-328.

31. Arciola CR, Campoccia D, Speziale P, Montanaro L, Costerton JW. Biofilm formation in Staphylococcus implant infections. A review of molecular mechanisms and implications for biofilmresistant materials. Biomaterials. 2012;33(26):5967-5982.

32. Campoccia D, Montanaro L, Arciola CR. A review of the biomaterials technologies for infection-resistant surfaces. Biomaterials. 2013;34(34):8533-8554.

33. Nakamura M, Shimakawa T, Nakano S, Chikawa T, Yoshioka S, Kashima M, et al. Screening for nasal carriage of Staphylococcus aureus among patients scheduled to undergo orthopedic surgery: Incidence of surgical site infection by nasal carriage. Journal of Orthopaedic Science. 2017;22(4):778-782.

34. Reina N, Delaunay C, Chiron P, Ramdane N, Hamadouche M; Société française de chirurgie orthopédique et traumatologique. Infection as a cause of primary total hip arthroplasty revision and its predictive factors. Orthopaedics \& Traumatology: Surgery \& Research. 2013;99(5):555-561.

35. de Foggi CC, Machado AL, Zamperini CA, Fernandes D, Wady $\mathrm{AF}$, Vergani $\mathrm{CE}$. Effect of surface roughness on the hydrophobicity of a denture-base acrylic resin and Candida albicans colonization. Journal of Investigative and Clinical Dentistry. 2016;7(2):141-148.
36. Insua A, Monje A, Wang HL, Miron RJ. Basis of bone metabolism around dental implants during osseointegration and peri-implant bone loss. Journal of Biomedical Materials Research Part A. 2017;105(7):2075-2089.

37. Smeets R, Stadlinger B, Schwarz F, Beck-Broichsitter B, Jung $\mathrm{O}$, Precht $\mathrm{C}$, et al. Impact of Dental Implant Surface Modifications on Osseointegration. BioMed Research International. 2016;2016:6285620.

38. Queiroz TP, de Molon RS, Souza FÁ, Margonar R, Thomazini $\mathrm{AH}$, Guastaldi AC, et al. In vivo evaluation of cp Ti implants with modified surfaces by laser beam with and without hydroxyapatite chemical deposition and without and with thermal treatment: topographic characterization and histomorphometric analysis in rabbits. Clinical Oral Investigations. 2017;21(2):685-699.

39. Sisti KE, de Rossi R, Antoniolli AM, Aydos RD, Guastaldi AC, Queiroz TP, et al. Surface and biomechanical study of titanium implants modified by laser with and without hydroxyapatite coating, in rabbits. The Journal of Oral Implantology. 2012;38(3):231-237.

40. Rong M, Zhou L, Gou Z, Zhu A, Zhou D. The early osseointegration of the laser-treated and acid-etched dental implants surface: an experimental study in rabbits. Journal of Materials Science. Materials in Medicine. 2009;20(8):1721-1728.

41. Braga FJC, Marques RFC, Almeida Filho E, Guastaldi AC. Surface modification of Ti dental implants by $\mathrm{Nd}: \mathrm{YVO}_{4}$ laser irradiation. Applied Surface Science. 2007;253(23):9203-9208.

42. Bini RA, Santos ML, Almeida Filho E, Marques RFC, Guastaldi AC. Apatite coatings onto titanium surfaces submitted to laser ablation with different energy densities. Surface and Coatings Technology. 2009;204(4):399-403.

43. Almeida Filho E, Fraga AF, Bini RA, Guastaldi AC. Bioactive coating on titanium implants modified by $\mathrm{Nd}: \mathrm{YVO}_{4}$ laser. Applied Surface Science. 2011;257(10):4575-4580.

44. Heinrich A, Dengler K, Koerner T, Haczek C, Deppe H, Stritzker B. Laser-modified titanium implants for improved cell adhesion. Lasers in Medical Science. 2008;23(1):55-58.

45. Györgyey Á, Ungvári K, Kecskeméti G, Kopniczky J, Hopp B, Oszkó A, et al. Attachment and proliferation of human osteoblastlike cells (MG-63) on laser-ablated titanium implant material. Materials Science and Engineering: C. 2013;33(7):4251-4259.

46. Gittens RA, Scheideler L, Rupp F, Hyzy SL, Geis-Gerstorfer J, Schwartz Z, et al. A review on the wettability of dental implant surfaces II: Biological and clinical aspects. Acta Biomaterialia. 2014;10(7):2907-2918.

47. Schwarz F, Wieland M, Schwartz Z, Zhao G, Rupp F, GeisGerstorfer J, et al. Potential of chemically modified hydrophilic surface characteristics to support tissue integration of titanium dental implants. Journal of Biomedical Materials Research Part B: Applied Biomaterials. 2009;88(2):544-557.

48. Wennerberg A, Jimbo R, Stübinger S, Obrecht M, Dard M, Berner S. Nanostructures and hydrophilicity influence osseointegration: a biomechanical study in the rabbit tibia. Clinical Oral Implants Research. 2014;25(9):1041-1050. 
49. Camurcu Y, Sofu H, Buyuk AF, Gursu S, Kaygusuz MA, Sahin V. Two-Stage Cementless Revision Total Hip Arthroplasty for Infected Primary Hip Arthroplasties. The Journal of Arthroplasty. 2015;30(9):1597-1601.

50. Stoodley P, Nistico L, Johnson S, Lasko LA, Baratz M, Gahlot $\mathrm{V}$, et al. Direct demonstration of viable Staphylococcus aureus biofilms in an infected total joint arthroplasty. A case report. The Journal of Bone and Joint Surgery. American Volume. 2008;90(8):1751-1758.

51. Rochford ET, Poulsson AH, Salavarrieta Varela J, Lezuo P, Richards RG, Moriarty TF. Bacterial adhesion to orthopaedic implant materials and a novel oxygen plasma modified PEEK surface. Colloids and Surfaces B: Biointerfaces. 2014;113:213-222.
52. Wu Y, Zitelli JP, TenHuisen KS, Yu X, Libera MR. Differential response of Staphylococci and osteoblasts to varying titanium surface roughness. Biomaterials. 2011;32(4):951-960.

53. Annunziata M, Rizzo A, Leone C, Mangano C, Mazzola N, Lastri L, et al. Bacterial adhesion to direct laser metal formed and mildly acid etched implant surfaces. Surface and Coatings Technology. 2017;328:390-397.

54. Geetha M, Singh AK, Asokamani R, Gogia AK. Ti based biomaterials, the ultimate choice for orthopaedic implants - A review. Progress in Materials Science. 2009;54(3):397-425.

55. Dakheel KH, Abdul Rahim R, Neela VK, Al-Obaidi JR, Hun TG, Yusoff K. Methicillin-Resistant Staphylococcus aureus Biofilms and Their Influence on Bacterial Adhesion and Cohesion. BioMed Research International. 2016;2016:4708425. 